\title{
Assessing meaning in life on an international scale: Psychometric evidence for the meaning in life questionnaire-short form among Chilean households
}

\author{
Michael F. Steger • Emma Samman
}

\begin{abstract}
Several research projects have endeavored to articulate parsimonious and comprehensive accounts of wellbeing. A set of core concepts is seen to be emerging, including the psychological wellbeing module of the Oxford Poverty and Human Development Initiative's international research on poverty. One of the core components of wellbeing according to this initiative and others is meaning in life. The present study focuses on a psychometric evaluation of a short measure of meaning in life to be used in international measurement of wellbeing, using data from a nationally-representative sample of households in Chile $(N=1,997)$. The factor structure of the Meaning in Life Questionnaire-Short Form (MLQ-SF) was confirmed, and shown to be invariant across gender and age. The items of the MLQ-SF formed a factor that was distinct from the items of other wellbeing measures that were assessed (psychological needs, life satisfaction, and domain satisfaction). Scores on the MLQ-SF were reliable in this sample, and correlated in the expected directions with other wellbeing indicators. We conclude that the MLQ-SF shows distinct promise as a measure of a core component of wellbeing-meaning in life - in international research.
\end{abstract}

Keywords: meaning in life; wellbeing; psychological needs; life satisfaction; Chile

\section{Introduction}

In the broadest sense, the term 'wellbeing' refers to people's optimal functioning and experience. However, defining wellbeing more precisely continues to stimulate extensive debate. Within psychology, the disease model has dominated, viewing wellbeing as the absence of illness rather than as the presence of any particular qualities (Ryff \& Singer, 1998; Ryan \& Deci, 2001). More recently, attention has shifted toward gaining a better idea of the characteristics that delineate positive functioning.

Psychologists have adapted two philosophical traditions to develop ideas about what constitutes wellbeing (Ryff \& Singer, 1998; Ryan \& Deci, 2001). The first tradition, known variously as the hedonic or subjective view, purports that wellbeing consists of subjective perceptions of happiness and the experience of pleasure (Diener, 2000). In psychological terms, hedonic wellbeing "may be expected to be felt whenever pleasant affect accompanies the satisfaction of needs, whether physically, intellectually, or socially based" (Waterman, 1993, p.2). The second tradition, known as the eudaimonic or psychological view, places greater emphasis on the cultivation of personal potential, virtue, and meaningful living (Ransome, 2010; Ryan \& Deci, 2001; Ryff \& Singer, 1998; Waterman, 1993). This eudaimonic tradition enlists concepts such as autonomy, personal growth, self-acceptance, life purpose, competence 
and mastery, belongingness and positive relatedness as important domains for understanding wellbeing (Ryff \& Singer, 1998; Ryan \& Deci, 2001). From the hedonic perspective, being virtuous and living a meaningful life can yield wellbeing as long as behaving in that manner is subjectively enjoyable. In contrast, from the eudaimonic perspective, enjoyment and pleasure are not necessary for wellbeing. Instead, people must have the opportunity to exercise personal choice, gain a sense of competence and mastery, cultivate healthy relationships, and find meaning and purpose in life.

At present, psychological research fails to empirically support theoretical arguments for differentiating between the two concepts as distinct kinds of wellbeing. Philosophers debate whether hedonic and eudaimonic conceptualizations provide a more correct account of human flourishing. Psychologists are more concerned with whether one tradition, the other, or both, best predict outcomes of interest, although some have appeared invested in promoting one or other tradition on its own as the most desirable outcome. As psychological research increasingly has taken an interest in understanding optimal functioning, evidence has accumulated that representative measures from each tradition provide complementary information (Kashdan, Biswas-Diener, \& King, 2008). For example, researchers have investigated the combination of hedonic and eudaimonic indicators in relation to meaning in life (Kashdan \& Steger, 2007; King, Hicks, Krull, \& Del Gaiso, 2006). Results suggest that hedonic and eudaimonic elements frequently function together, and therefore that optimal functioning is best achieved through combining both approaches (Keyes, Shmotkin, \& Ryff, 2002). Furthermore, the study highlights the relevance of investigating how facets of eudaimonia and hedonism work in unison (Kashdan et al., 2008). Although much of the research in this area has assumed that eudaimonic dimensions are antecedents of hedonic wellbeing (Kashdan et al., 2008; Zika \& Chamberlain, 1992), it is also plausible that hedonic variables might bring about eudaimonic wellbeing. For example, a meta-analysis has shown that positive emotions - key indicators of hedonic wellbeing-were antecedents in attaining career success and satisfying marriages (Lyubomirsky, King, \& Diener, 2005). It follows that it may be most desirable to study elements of both hedonic and eudaimonic approaches when seeking to conceptualize wellbeing more broadly.

\subsection{OPHI and the assessment of wellbeing}

From 2007 on, the Oxford Poverty and Human Development Initiative (OPHI) has sought to develop a brief set of measures that could provide a broad conceptualization of wellbeing, and of deprivation, as part of its larger Missing Dimensions of Poverty research program. The Missing Dimensions program aims to devise modules to measure five so-called 'missing dimensions' of poverty: quality of work, empowerment, the 'ability to go about without shame,' physical safety, and-most relevant to the current study-psychological wellbeing. These dimensions emerge as crucially important in the experiences of poor people but data are not systematically collected to measure them at the individual and household levels in internationally-comparable survey instruments (Alkire, 2007). ${ }^{1}$ By collecting these data and exploring the patterns of deprivations and interconnections that emerge, the aim is to provide a broad account of human flourishing that is deeply grounded in poor people's realities (see Oxford Poverty and Human Development Initiative, 2007). 'Shortlists' of indicators were

\footnotetext{
${ }^{1}$ Alkire (2007) gives support for the importance of these dimensions - pointing in particular to the seminal Voices of the Poor study (Narayan et al., 2000). For more details of each dimension, see the respective articles in Oxford Poverty and Human Development Initiative (2007).
} 
proposed on the basis of a sweeping review of the survey-based literature. They have been subjected to expert review in a number of international contexts and are currently being administered and analyzed in several countries. ${ }^{2}$

The OPHI psychological wellbeing module is perhaps unique in combining hedonic and eudaimonic measures in a brief format that aims to be included in standard household surveys to generate internationally comparable results. The motivation is to understand how psychological factors - both hedonic and eudaimonic - relate to one another, and how they complement the more traditional objective indicators of wellbeing and of poverty that are derived from household surveys. In doing so, this module seeks to bring psychological factors into the picture as contextual variables that stand to contribute a richer perspective to an understanding of human experience and values, and particularly the importance of its nonmaterial components.

To measure eudaimonic wellbeing, OPHI adopts a two-pronged approach based on 1) the perception of meaning in life and 2) the ability to strive toward excellence in fulfilling this idea (Samman, 2007). To measure these concepts, the module incorporates Steger's Meaning in Life Questionnaire and Deci and Ryan's measures of autonomy, competence and relatedness, the three psychological needs associated with goal identification and pursuit, which in turn predict 'optimal functioning'. To measure hedonic wellbeing, the module contains separate indicators of satisfaction and happiness - drawing on Diener and Seligman's (2004) argument that they represent cognitive and affective aspects, respectively - including measures of satisfaction in life overall and in several distinct domains that past work has shown to be important (see Samman, 2007). Testing these modules in developing countries is essential. ${ }^{3}$ Though the psychological scales have been subject to extensive psychometric testing, this has been largely among samples consisting of US college students. The hedonic measures, too, require further study in non-Western contexts.

\subsection{Meaning in life in international wellbeing research}

Despite several decades of empirical and theoretical emphasis on the importance of meaning in life (e.g., Frankl, 1963; Deci \& Ryan, 2000; Ryan \& Deci, 2001; Ryff \& Singer, 1998; Steger, 2009, 2012; Steger, Frazier, Oishi, \& Kaler, 2006), the bulk of meaning in life research has focused on only a small handful of countries. In addition to a rather limited range of international samples (e.g., Hong Kong - Shek, 1995; Romania - Brassai, Piko, \& Steger, 2011; Slovakia, Hungary Halama, Martos, \& Adamovova, 2010; Martos, Thege, \& Steger, 2010; Spain - Steger, Frazier, \& Zacchanini, 2008), only one report has systematically investigated cross-national differences using a measure shown to be psychometrically robust, revealing that American samples reported higher levels of meaning in life than Japanese samples (Steger, Kawabata, Shimai, \& Otake, 2008). This evidence of at least some degree of cross-national differences in meaning in life-among two fully industrialized countries-points toward the need for a greater investment in systematic efforts to understand meaning internationally.

The implications could be substantial. Not only do those who feel their lives are meaningful report greater wellbeing and lesser psychological distress (e.g., Steger et al., 2006; see Steger, in press, for review), but they also report better post-trauma adjustment (Steger, Frazier, et al.,

\footnotetext{
${ }^{2}$ For the full set of modules in English, French, Igbo, Tagalog, Tamil, Sinhala and Spanish, and a description of work to date under the Missing Dimensions, see www.ophi.org.uk.

${ }^{3}$ Existing studies of cross-national wellbeing include Deaton 2008, Diener 2009, Graham 2009, Diener et al 2010 and the work of the International Wellbeing Group, available at: http://www.deakin.edu.au/research/acqol/iwbg/index.php.
} 
2008), better health (Steger, Mann, Michels, \& Cooper, 2009), and dramatically lower risk of cognitive decline and incidence of Alzheimer's Disease (Boyle, Buchman, Barnes, \& Bennett, 2010) and death (Boyle, Barnes, Buchman, \& Bennett, 2009). Meaning in life appears to be a notable psychological resource, yet most research on this important variable has been conducted in industrialized Western nations. It remains to be seen what kind of resource meaning in life is in most of the world. One possible explanation for this apparent neglect is that the Western idea that meaning in life is marked by making sense of one's life and pursuing a valued life purpose may be seen in different terms in other cultures. The research cited above suggests that people from diverse cultures can respond to measures of Western notions of meaning in life, but indigenous models of meaning may need to be developed to supplement this research.

A second reason for the small amount of international research on meaning is the absence of psychometrically sound, brief measures of meaning in life. Prior to the publication of the Meaning in Life Questionnaire (MLQ; Steger, Frazier, Oishi, \& Kaler, 2006), measures of meaning in life were criticized for having poor content validity (Dyck, 1987) and structural properties (Steger, 2007). Although it is relatively brief, the MLQ uses five items each to assess the 'presence of meaning' (how meaningful one feels one's life is) and the 'search for meaning' (how intently one is seeking greater meaning in life). Even five items can be too demanding for large-scale international research. Therefore, the OPHI collaborated with Steger to develop a short form of the MLQ presence of meaning subscale containing three items and a simplified response structure (4 points rather than 7 ). ${ }^{4}$ The present study provides an in-depth psychometric analysis of this new measure, for the purpose of evaluating its utility in multidimensional poverty analysis as well as international public health and population surveillance research. Because no previous research has reported on meaning in life, we cannot draw upon existing research to formulate hypotheses. Meaning in life is regarded as a universally-valued aspect of human experience, therefore we anticipated that there would be positive correlations among all of the measures of wellbeing included in the present study.

\section{Method}

\subsection{Participants and procedure}

Following several small-scale pilots, OPHI has undertaken small subnational surveys of its Missing Dimensions modules-alongside standard survey modules (income or consumption, health, education, etc.) in several cross-national contexts-notably Philippines, Chad, Nigeria and Sri Lanka. In 2009, OPHI undertook a nationally-representative survey of Chile, involving some 2000 households, in conjunction with the Centro de Microdatos of the Department of Economics, University of Chile. These households were a subsample of those interviewed in Chile's 2006 national household survey (Encuesta de Caracterización Socioeconómica Nacional, CASEN), with stratification conducted on the basis of urban-rural zone and income quintile. ${ }^{5}$ The 2009 survey integrated Missing Dimensions modules with standard questions on income, health, education, housing and employment from Chile's national household survey (Encuesta

\footnotetext{
${ }^{4}$ Limited work has been carried out on the optimal response structure for psychological and subjective questions. Given this lack of rigorous study, the relatively low levels of education in some developing country settings and evidence that people in different cultural contexts may not perceive such scales to be linear with equi-distant intervals, a cautious approach suggests a reduced set of options with labels attached to each interval.

5 The sample frame for the 2006 CASEN was the 2002 census - its sample was drawn using multi-stage random sampling with geographic stratification and clustering. For more information regarding the OPHI survey, please see: http://www.ophi.org.uk/research/missing-dimensions/projects/.
} 
de Caracterización Socioeconómica Nacional, CASEN). ${ }^{6}$ The respondent was any adult member of a selected household and he or she responded to questions about perceptions (including the whole Psychological Wellbeing Module) for him or herself only. The collection of these data provides an opportunity to examine the psychometric properties of the short form of the MLQ in a nationally representative sample of households in Chile. The final sample consisted of $1,997$ individuals (51.8\% female; age $M=47.6$; $S D=13.2)$.

Chile is a long, narrow country in Latin America's Southern cone, extending some 2650 miles from north to south and just 110 miles east to west. The country is bordered to the north by Peru and Bolivia, and to the east by Argentina. Chile has a population of some 17 million people, some 40 percent of whom live in or around the capital of Santiago, and is relatively homogeneous compared to many other Latin American societies. Nearly 60 percent of its people identify themselves as white, 25 percent as Mestizo and 8 percent as Indigenous. ${ }^{7}$ Most are Catholic (some 70 percent) or evangelical (15 percent), according to the most recent 2002 census. Chile is one of Latin America's top economic performers -its per capita GDP of some 16,000 USD places it second only to Argentina in Latin America, ${ }^{8}$ and its Human Development Index (HDI) of .805 reflects a "very high" level of human development. At the same time, a recent survey suggests overall life satisfaction is relatively low by regional standards, higher only than that of Peru. ${ }^{9}$ Though much of its 'miraculous' economic growth occurred under the authoritarian Pinochet regime (1973-1990), income poverty rose markedly during this period and did not begin to recover until 1990, when Chile reverted to a stable democracy. Since then, the poverty headcount fell from over 40 percent to around 15 percent, as of 2009 (Gobierno de Chile, 2010).

\subsection{Measures}

All measures discussed below were translated into Spanish and then backtranslated into English by translators associated with OPHI. The translations were checked with researchers at $\mathrm{OPHI}$ and at the Centro de Microdatos, University of Chile.

Meaning in Life Questionnaire - Short Form (MLQ-SF). Three items from the MLQ (Steger et al., 2006) presence subscale were included in the study, with slight modifications to improve comprehensibility following translation: "My life has a clear meaning or purpose," "I have found a satisfactory meaning in life," and "I have a clear sense of what gives meaning to my life." Items were rated from 1 (Not at all true) to 4 (Completely true). Recently, the MLQ short form was used in national health surveillance research in the United States, revealing very good reliability and validity in those samples (Kobau, Sniezek, Zack, Lucas, \& Burns, 2010).

Basic Psychological Needs Scale - Short Form. This scale was developed to assess the three psychological needs of autonomy, competence and relatedness, drawing upon SelfDetermination Theory (Deci \& Ryan, 2000). The original scale consisted of 21 items (Gagné, 2003). Deci and Ryan proposed to OPHI a shorter version (BPN-SF) for use in its module, using three items each to assess the needs of autonomy $(\alpha=.93$; e.g., "I am free to decide for myself how to lead my life"), competence ( $\alpha=.82$; e.g., "People I know tell me I am competent/capable

\footnotetext{
${ }^{6}$ For more information regarding the survey, please see: http://www.ophi.org.uk/research/missingdimensions/projects/.

${ }^{7}$ Corporación LatinoBarometro (2011), p. 58. Other groups make up 2 percent or less of the population.

8 Per capita GDP is in current US dollars at Purchasing Power Parity (PPP) World Development Indicators 2011 (http://databank.worldbank.org), HDI data is available at hdr.undp.org/statistics/.

${ }_{9}$ According to most recent Gallup World Poll data, Chile's average life satisfaction is 6.3 out of ten, higher only than that Peru (5.9), out of 19 Latin American and Caribbean countries (https://worldview.gallup.com).
} 
at what I do"), and relatedness ( $\alpha=.94$; e.g., "I get along well with people I come into contact with"). Items were rated from 1 (Not at all true) to 4 (Completely true).

Life and Domain Satisfaction Items. Based on a survey of the literature on philosophical, participatory and psychological accounts of wellbeing, Samman (2007) provides a central list of life domains that previous reviews identify as important. ${ }^{10}$ Participants were asked to rate the following items from 1 (Very satisfied) to 4 (Not at all satisfied): life overall, food, housing, income, health, work, local security, friends, family, education, free choice and control over life, dignity, neighborhood/town/community, ability to help others, and spiritual/religious/ philosophical beliefs. Domains were selected under the assumption that they would contribute unique variance to overall wellbeing, hence internal consistency is not necessarily a relevant consideration. At the same time, the estimate of internal consistency $(\alpha=.58)$ indicated that people's satisfaction with different domains tends to cluster to some extent.

\section{Results}

\subsection{Data analysis plan}

In order to evaluate the properties of the MLQ-SF, we conducted a series of analyses. First we sought to establish the structural validity of the new measure using confirmatory factor analysis (CFA). We then evaluated the internal consistency of the measure, and used exploratory factor analysis to gauge its distinctiveness from other wellbeing measures incorporated in the OPHI survey module, as implemented in Chile. Finally, we sought to establish the measurement invariance of the MLQ-SF across age and gender using multigroups applications of CFA. In addition, we conducted a preliminary descriptive examination of relations between the MLQ-SF and other wellbeing measures.

\subsection{Psychometric evaluation of the MLQ-SF}

\subsubsection{Structure of the MLQ-SF}

A CFA was conducted on a model in which these three items were loaded on by a common, meaning in life, factor. Regression estimates were fixed for all error estimates, as well as two factor-to-item paths in order to free a degree of freedom necessary for evaluating goodness of fit. The model was first tested in the entire sample $(N=1,997)$. This was necessary to gain degrees of freedom needed to calculate modification indices. As recommended in previous research, we used the Comparative Fit Index (CFI), Non-Normed Fit Index (NNFI), Root Mean Square Approximation of Error (RMSEA), and Standardized Root Mean Squared Residual (SRMR) to evaluate the fit of the MLQ across cultures (Hu \& Bentler, 1999; Little, 1997). Because of the large sample size, the chi-square was significant. RMSEA also indicated some improvement could be made to the model. However, other goodness of fit indices were within range for an excellent fit of the model to the data $\left(X^{2}(d f=1, N=1,997)=26.10, p<.001 ; \mathrm{CFI}=\right.$ $.99 ; \mathrm{NNFI}=.97$; SRMR $=.01$; RMSEA $=.11,90 \%$ C.I. $=.08-.15)$. Regression estimates for paths from the factor to the items ranged from .82 to .90 . Thus, the simple model of three items loading a single factor fits adequately for research purposes.

According to modification indices, however, additional paths should be included in the model among each of the items and each of the error estimates as well as with the factor overall. This model would obviously lack parsimony. However, given the close semantic similarity of items 1 and 3 (both refer to 'clarity'), a second model was run in which the error

\footnotetext{
${ }^{10}$ On philosophical and participatory approaches, see in particular Alkire 2002, on psychological approaches, Cummins 1996.
} 
terms from these two items were allowed to correlate. Again, in order to release a degree of freedom, the third factor-to-item path was fixed. This model fit the data very well, exceeding all benchmarks $\left(X^{2}(d f=1, N=1,997)=5.57, p<.05 ; \mathrm{CFI}=.999\right.$; $\mathrm{TLI}=.997$; SRMR $=.01$; RMSEA $=$ $.05,90 \%$ C.I. $=.02-.09$ ). Regression estimates for paths from the factor to the items ranged from .84 to .90 . Although this model is not the most parsimonious, it does maximize fit to the data, and demonstrates that these three items are closely related, and all items are strongly associated with the same latent factor, meaning in life.

\subsubsection{Reliability}

Next, the internal consistency was calculated for the three meaning items, with Cronbach's alpha (.88), inter-item correlations (rs from .66 to .73), and single measure interclass correlation coefficient (.71) indicating a high degree of coherence among the items. The internal consistency of the MLQ-SF in this Chilean sample is nearly identical to that reported in a national American sample $(\alpha=.89$; Kobau et al., 2010).

\subsubsection{Distinctiveness of the MLQ-SF from related measures}

Finally, an exploratory factor analysis (maximum likelihood extraction with promax rotation, kappa $=4$ ) was conducted with the three MLQ items, as well as the nine items from the short form of the basic psychological needs scale and the 15 items from the life domain satisfaction measure. A total of nine factors were extracted according to the heuristic of eigen values greater than 1. Items from the MLQ-SF, and the items from each of the three BNS-SF subscales, formed clear factors with strong, primary, pattern matrix loadings for the MLQ-SF (.81-.91), the relatedness (.83-1.00), autonomy (.90-.92), and competence (.65-.91) subscales, with negligible secondary loadings (all <.08).

The items from the life domain satisfaction measure had smaller primary factor loadings (.16-.50), and a less distinct factor pattern. The best-formed factor consisted of satisfaction with housing, life over-all, income, food, education, and health. Only two other factors had multiple items with primary loadings greater than .30 . The first consisted of satisfaction with ability to help others and spiritual/religious/philosophical beliefs. The other consisted of satisfaction with local security level and neighborhood/town/community. Satisfaction with work, friends, family, and free choice and control over life did not load on any factors above .30. Further investigation is needed to explain these patterns; however, there is no strong reason to expect shared variance.

It is clear from these analyses that meaning in life and basic psychological needs are distinct from each other, and from the satisfaction items.

\subsubsection{Invariance of MLQ-SF scores across gender}

To establish measurement invariance of the MLQ-SF across gender, we conducted a series of multigroup confirmatory factor analyses (see Byrne, Shavelson, \& Muthén 1989; Cheung \& Rensvold, 2002) on the dataset comparing male and female respondents using AMOS 17 (Arbuckle, 2010). The first model tested consisted of the single-factor structure of the MLQ-SF, as described above, allowing all parameters to vary across cultural groups. According to these indices, the two-factor model fit well across gender $(\mathrm{CFI}=.999, \mathrm{NNFI}=.996$, SRMR $=.00$, RMSEA $=.03,90 \%$ C.I. $=.00-.06$ ). With this level of weak, or configural, invariance, comparing correlations using the scale is tenable. We next tested the same model, but with factor loadings constrained to be equal across gender. The model fit was identical. Finally, to establish strong, 
also known as scalar, invariance, the regression intercepts were fixed across gender. This model also had excellent fit $(\mathrm{CFI}=.998, \mathrm{NNFI}=9.97, \mathrm{SRMR}=.00, \mathrm{RMSEA}=.03,90 \%$ C.I. $=.01-.05)$, demonstrating measurement equivalence across gender in this sample.

\subsubsection{Invariance of MLQ-SF scores across age groups}

Using the same procedure as described above, a series of analyses was conducted to determine the factorial invariance of the MLQ-SF across age groups. The following age categories were created from the complete dataset: 18-29 years, 30-44 years, 45-59 years, and 60 years and older. When people with missing data were excluded, there were no individuals younger than 19 years old. Thus, the de facto age groups were 19-29 years $(n=175), 30-44$ years $(n=674), 45-59$ years $(n=774)$, and 60 years and older $(n=374)$. With all parameters allowed to vary across age groups, the fit of the model was excellent $(\mathrm{CFI}=.998, \mathrm{NNFI}=.994, \mathrm{SRMR}=.02$, RMSEA $=.03$, $90 \%$ C.I. $=.01-.05)$. The fit was identical when factor loadings were fixed across age groups (CFI $=.998, \mathrm{NNFI}=.994, \mathrm{SRMR}=.02, \mathrm{RMSEA}=.03,90 \%$ C.I. $=.01-.05)$. Finally, even with the regression intercepts fixed across age groups, the fit was still excellent (CFI $=.993$, NNFI $=.994$, SRMR $=.02$, RMSEA $=.03,90 \%$ C.I. $=.02-.04)$. The MLQ-SF appears to demonstrate measurement equivalence across age groups.

Thus, the MLQ-SF shows the same desirable psychometric properties that the long form of the MLQ does: internal consistency, structural validity, and measurement invariance across age and gender (Kobau et al., 2010; Steger \& Frazier, 2005; Steger et al., 2006; Steger, Oishi, \& Kashdan, 2009).

\subsection{Descriptive statistics for the MLQ-SF}

Across the sample, mean scores on the MLQ-SF were $9.64(S D=2.13)$, which corresponds to an average item rating of 3.21, or somewhat higher than "Fairly True." The average rating for item one (My life has a clear meaning or purpose) was 3.17, for item two (I have found a satisfactory meaning in life) the average rating was 3.14, and for item three (I have a clear sense of what gives meaning to my life), the average rating was 3.32. The total score for the MLQ-SF was negatively skewed (skewness $=-.677, S E_{\text {skewness }}=.055$ ), as were each of the items (range of skewness $=-.695$ to -.898 , range of $S E_{\text {skewness }}=.054$ to .055 ). The total score for the MLQ-SF did not have significant kurtosis (kurtosis $=.034, S E_{\text {kurtosis }}=.109$ ), and neither did items one or two (range of kurtosis $=-.109$ to -.032 , SEkurtosis $=.108$ to .109$)$, although item three did $($ kurtosis $=.321$, SEkurtosis $=$ .109). Thus, respondents in general were typically of the opinion that their lives were meaningful, rather than meaningless. In fact, the positivity of endorsement raises some question of whether there was a ceiling effect on participants' responses such that variance in response was constrained. The significantly skewed scores on each item bear this out. Research using the typical 7-choice response anchors of the full MLQ does not reveal a consistent pattern of skewness or kurtosis (e.g., Steger et al., 2006), However, without additional research in other Chilean samples, it is unclear whether adding more response options would ameliorate this tendency toward MLQ-SF scores hitting a ceiling, or whether there is a naturally skewed distribution of the variable in real life, regardless of response options.

\subsection{Demographic factors and meaning in life}

The next set of analyses examined whether meaning in life scores varied by age, gender, or other demographic factors. There was a significant, negative correlation between age and MLQSF scores, although the magnitude of this relation was less than small $(r=-.07, p<.01)$. Women 
reported significantly higher MLQ-SF scores than men $(t(1995)=2.12, p<.05)$, although the magnitude of this difference was less than small $(d=.09)$. Although the omnibus F-test for differences among married, single, widowed, divorced, annulled, and cohabitating respondents was significant $(F(6,1990)=5.56, p<.05)$, Tukey's B post hoc tests did not reveal any significant subsets of respondents, and widely differing numbers of respondents in each category (ranging from 2 to 1308) interfered with any conclusions that might be drawn from the omnibus test. Thus, although there were significant relations with demographic factors, the effect sizes were less than small, suggesting that the influence of demographic factors was limited.

\subsection{Meaning in life and wellbeing}

After employing sample weights, correlation coefficients were calculated among meaning in life, the basic psychological needs, and the indicators of satisfaction. As can be seen in Table 1, meaning in life, the three psychological needs, and overall life satisfaction were intercorrelated with medium to large effect sizes. The largest correlate of meaning in life was autonomy ( $r=$ .68). This finding was echoed in the correlations with domain satisfaction ratings (see Table 2), where satisfaction with free choice and control over life was the strongest correlate of meaning in life $(r=.44)$, with the rest of the correlations with domain satisfaction ranging from .20 to 39 . The pattern of correlations indicated that eudaimonic variables were related more strongly with each other than they were with hedonic variables, and vice versa.

Table 1. Correlations among meaning, psychological need satisfaction, and overall life satisfaction

\begin{tabular}{lcccc}
\hline \hline & $\mathbf{1}$ & $\mathbf{2}$ & $\mathbf{3}$ & $\mathbf{4}$ \\
\hline 1. Meaning in Life & & & & \\
2. Relatedness & .50 & & & \\
3. Autonomy & .68 & .53 & & \\
4. Competence & .53 & .67 & .60 & \\
5. Life Satisfaction & .43 & .34 & .44 & .40 \\
\hline \hline
\end{tabular}

Note. All correlation coefficients are significant at $\mathrm{p}<.001$ level.

\section{Discussion}

The wellbeing of nations is of abiding interest across diverse disciplines, spanning sociology, economics, and epidemiology on one end and psychology, medicine, and philosophy on the other end. Increasingly sophisticated efforts are being made to model wellbeing for research and policy purposes (e.g., Alkire \& Santos 2010; Gallup, Inc., 2007; Kobau et al., 2010). Although these new approaches are increasingly multidimensional, the inclusion of meaning in life in these efforts has been hampered by the lack of a solid measure with high utility. The present study builds on previous national-level research showing that the MLQ-Presence short form scale can be effectively used in large-scale research (Kobau et al., 2010). We were able to show that the MLQ-SF has a strong structure, that the factor structure was invariant across gender and age, that it is factorially distinct from psychological need satisfaction and life and domain satisfaction, and that meaning in life is positively associated with other components of wellbeing, in a previously unexplored national context. We believe that this is an important first step in deploying the MLQ-SF in national and cross-national studies of health and wellbeing. 
Table 2. Correlations between meaning in life and domain life satisfaction

\begin{tabular}{lc}
\hline \hline & Meaning in Life \\
\hline Housing & .30 \\
Income & .28 \\
Health & .30 \\
Work & .30 \\
Local Security Level & .20 \\
Friends & .31 \\
Family & .34 \\
Education & .30 \\
Free Choice and Control over Life & .44 \\
Dignity & .39 \\
Neighborhood/Town/Community & .27 \\
Ability to Help Others & .35 \\
Spiritual/Religious/Philosophical Beliefs & .34 \\
\hline \hline
\end{tabular}

Note. All correlation coefficients are significant at $\mathrm{p}<.001$ level.

As an ancillary finding, psychometric evidence for the brief measure of psychological need satisfaction also appears encouraging, at least at the level of internal consistency reliability and exploratory factor analysis. The three putative subscales formed distinct factors with high internal loadings and low cross-loadings. Finally, taken as a whole, factor analyses and the pattern of correlations among measures supported the theoretical notion that hedonic and eudaimonic notions of wellbeing are distinct yet related. It also could be that linguistic similarities in the way that the satisfaction items were composed increased their intercorrelation. This does not explain why the eudaimonic variables were more highly related to each other than they were to the hedonic variables, but it could partly explain why the satisfaction items formed additional factors in the exploratory factor analysis.

More research is of course needed. Among the most pressing issues is that the kind of multidimensional data presented here, using psychometrically robust measures of psychological wellbeing, are not available in other countries. This limits any conclusions drawn from these data to a Chilean context. There are fairly well-established national variations in some wellbeing indicators (e.g., life satisfaction ratings, Diener, Diener, \& Diener, 1995), and it is important to establish whether these variations obtain for the range of indicators in the present module. Future research also should begin providing information about relationships among the psychological wellbeing components and outcomes of interest, such as health, mortality, education, income poverty, and other socioeconomic factors. In addition, future research should gauge whether each psychological component makes a unique contribution to these outcomes, or whether specific outcomes are best predicted by particular components.

The present study begins the task of internationally validating to an easily implementable tool for measuring meaning in life. It strongly suggests that MLQ-SF may be an appropriate tool for this purpose and places meaning in life among other important indicators of wellbeing.

\section{Authors}

Michael F. Steger

Colorado State University

michael.f.steger@colostate.edu 
Emma Samman

Overseas Development Institute

\section{Publishing Timeline}

Received 8 February 2012

Accepted 28 April 2012

Published 29 August 2012

\section{References}

Alkire, S. (2002). Valuing Freedoms: Sen's Capability Approach and Poverty Reduction (Oxford: Oxford University Press).

Alkire, S. (2007). The missing dimensions of poverty data: introduction to the special issue, Oxford Development Studies 35(4): 379-403. http://dx.doi.org/10.1080/13600810701701863

Alkire, S., \& Santos, M. E. (2010). Acute multidimensional poverty: a new index for developing countries. OPHI Working Paper 38.

Arbuckle, J. L. (2010). AMOS 17. Chicago, IL: IBM Corp.

Boyle, P. A., Barnes, L. L., Buchman, A. S., \& Bennett, D. A. (2009). Purpose in life is associated with mortality among community-dwelling older persons. Psychosomatic Medicine, 71, 547-579. http://dx.doi.org/10.1097/PSY.0b013e3181a5a7c0

Boyle, P. A., Buchman, A. S., Barnes, L. L., \& Bennett, D. A. (2010). Effect of a purpose in life on risk of incident Alzheimer Disease and mild cognitive impairment in community-dwelling older persons. Archives of General Psychiatry, 67, 304-310. http://dx.doi.org/10.1001/archgenpsychiatry.2009.208

Brassai, L., Piko, B. F., \& Steger, M. F. (2011). Meaning in life: Is it a protective factor for adolescents' psychological health? International Journal of Behavioral Medicine, 18, 44-51. http://dx.doi.org/10.1007/s12529-010-9089-6

Byrne, B. M., Shavelson, R. J., \& Muthén, B. (1989). Testing for the equivalence of factor covariance and mean structures: The issue of partial measurement invariance. Psychological Bulletin, 105, 456-466. http://dx.doi.org/10.1037/0033-2909.105.3.456

Cheung, G. W., \& Rensvold, R. B. (2002). Evaluating goodness-of-fit indexes for testing measurement invariance. Structural Equation Modeling, 9, 233-255.

Corporación Latinobarometro (2011). Informe 2011. Santiago, Chile.

Deaton, A. (2008). Income, health and wellbeing around the world: Evidence from the Gallup World Poll, Journal of Economic Perspectives 22(2), 53-72. http://dx.doi.org/10.1257/jep.22.2.53

Deci, E. L. \& Ryan, R. M. (2000). The 'what' and 'why' of goal pursuits: Human needs and the selfdetermination of behavior, Psychological Inquiry 11, 227-268.

Diener, E. (2000). Subjective well-being: The science of happiness and a proposal for a national index. American Psychologist, 55, 34-43. http://dx.doi.org/10.1037/0003-066X.55.1.34

Diener, E. (Ed.) (2009). Culture and well-being: The collected works of Ed Diener. Social indicators research series (Vol. 38). Dordrecht, the Netherlands: Springer.

Diener, E., Diener, M., \& Diener, C. (1995). Factors predicting the subjective wellbeing of nations. Journal of Personality and Social Psychology, 69, 851-864. http://dx.doi.org/10.1037/0022-3514.69.5.851

Diener, E., Helliwell, J. F. \& Kahneman, D. (Eds.) (2010). International differences in well-being, Oxford University Press.

Diener, E. and Seligman M .E. P. (2004). Beyond money: Towards an economy of wellbeing, Psychological Science in the Public Interest 5, 1-31. http://dx.doi.org/10.1111/j.0963-7214.2004.00501001.x

Dyck, M. J. (1987). Assessing logotherapeutic constructs: Conceptual and psychometric status of the Purpose in Life and Seeking of Noetic Goals Tests. Clinical Psychology Review, 7, 439-447. http://dx.doi.org/10.1016/0272-7358(87)90021-3

Frankl, V. E. (1963). Man's search for meaning: an introduction to logotherapy. New York: Washington Square Press. 
Gagné, M. (2003). The role of autonomy support and autonomy orientation in prosocial behavior engagement. Motivation and Emotion, 27, 199-223.

Gallup, Inc. (2007). The state of global wellbeing. New York: Gallup Press.

Gobierno de Chile (2010). CASEN 2009, Encuesta de Caracterización Socioeconómica Nacional, Santiago: mideplan.

http://www.ministeriodesarrollosocial.gob.cl/casen2009/RESULTADOS CASEN 2009.pdf.

Graham, C. (2009). Happiness around the world: The paradox of happy peasants and miserable millionaires, Oxford: Oxford University Press.

Halama, P., Martos, T., \& Adamovova L. (2010). Religiosity and wellbeing in Slovak and Hungarian student samples: The role of personality traits. Studia Psychologica, 52, 101-115.

Hu, L., \& Bentler, P. M. (1999). Cutoff criteria for fit indices in covariance structure analysis: Conventional criteria versus new alternatives. Structural Equation Modeling, 6, 1-55. http://dx.doi.org/10.1080/10705519909540118

Kashdan, T. B., Biswas-Diener, R., \& King, L. A. (2008). Reconsidering happiness: The costs of distinguishing between hedonics and eudaimonia. Journal of Positive Psychology, 3, 219-233. http://dx.doi.org/10.1080/17439760802303044

Kashdan, T. B., \& Steger, M. F. (2007). Curiosity and stable pathways to well-being and meaning in life: Traits, states, and everyday behaviours. Motivation and Emotion, 31, 159-173.

Keyes, C. L. M., Shmotkin, D., \& Ryff, C. D. (2002). Optimizing well-being: The empirical encounter of two traditions. Journal of Personality and Social Psychology, 82, 1007-1022. http://dx.doi.org/10.1037/0022-3514.82.6.1007

King, L. A., Hicks, J. A., Krull, J. L., \& Del Gaiso, A. K. (2006). Positive affect and the experience of meaning in life. Journal of Personality and Social Psychology, 90, 179-196. http://dx.doi.org/10.1037/00223514.90.1.179

Kobau, R., Sniezek, J., Zack, M. M., Lucas, R. E., \& Burns, A. (2010). Wellbeing assessment: An evaluation of wellbeing scales for public health and population estimated of wellbeing among US adults. Applied Psychology: Health and Wellbeing, 2, 272-297. http://dx.doi.org/10.1111/j.1758-0854.2010.01035.x

Little, T. D. (1997). Mean and covariance structures (MACS) analyses of cross-cultural data: Practical and theoretical issues. Multivariate Behavioral Research, 32, 53-76.

http://dx.doi.org/10.1207/s15327906mbr3201_3

Lyubomirsky, S., King, L. A., \& Diener, E. (2005). The benefits of frequent positive affect. Psychological Bulletin, 131, 803-855. http://dx.doi.org/10.1037/0033-2909.131.6.803

Martos, T., Thege, B. K., \& Steger, M. F. (2010). It's not only what you hold, it's how you hold it: Dimensions of religiosity and meaning in life. Personality and Individual Differences, 49, 863-868. http://dx.doi.org/10.1016/j.paid.2010.07.017

Narayan, D., Chambers, R., Shah, M. K., Petesch, P. (2000). Crying out for change: Voices of the poor. World Bank Publication, Washington D.C.

Oxford Poverty and Human Development Initiative (2007). Special Issue: The missing dimensions of poverty data, Oxford Development Studies 35, 347-359. http://www.tandfonline.com/toc/cods20/35/4

Ransome, B. (2010). Sen and Aristotle on wellbeing, The Australian Journal of Social Issues, 45: 1, 41-52. http://search.informit.com.au/documentSummary;dn=077290546393034;res=IELHSS

Ryan, R. M., \& Deci, E. L. (2001). On happiness and human potentials: A review of research on hedonic and eudaimonic wellbeing. Annual Review of Psychology, 52.

Ryff, C. D., \& Singer, B. H. (1998). The contours of positive human health. Psychological Inquiry, 9, 1-28. http://dx.doi.org/10.1207/s15327965pli0901 1

Samman, E. (2007), Psychological and subjective wellbeing: A proposal for internationally comparable indicators. Oxford Development Studies 35, 459-486. http://dx.doi.org/10.1080/13600810701701939

Shek, D. T. L. (1995). Marital quality and psychological wellbeing of married adults in a Chinese context. Journal of Genetic Psychology, 156, 45-56. http://dx.doi.org/10.1080/00221325.1995.9914805

Steger, M. F. (2007). Structural validity of the Life Regards Index. Measurement and Evaluation in Counseling and Development, 40, 97-109. 
Steger, M. F. (2009). Meaning in life. In Lopez. S. J. (Ed.) Oxford handbook of positive psychology (2nd Ed.) Oxford, UK: Oxford University Press, 679-687.

Steger, M. F. (2012). Experiencing meaning in life: Optimal functioning at the nexus of spirituality, psychopathology, and well-being. In Wong, P. T. P. \& Fry, P. S. (Eds.) The human quest for meaning (2nd Ed) New York: Routledge, 165-184.

Steger, M. F., \& Frazier, P. (2005). Meaning in life: One link in the chain from religion to wellbeing. Journal of Counseling Psychology, 52, 574-582. http://dx.doi.org/10.1037/0022-0167.52.4.574

Steger, M. F., Frazier, P., Oishi, S., \& Kaler, M. (2006). The Meaning in Life Questionnaire: Assessing the presence of and search for meaning in life. Journal of Counseling Psychology, 53, 80-93.

http://dx.doi.org/10.1037/0022-0167.53.1.80

Steger, M. F., Frazier, P., \& Zacchanini, J. L. (2008). Terrorism in two cultures: Traumatization and existential protective factors following the September 11th attacks and the Madrid train bombings. Journal of Trauma and Loss, 13, 511-527.

Steger, M. F., Kawabata, Y., Shimai, S., \& Otake, K. (2008). The meaningful life in Japan and the United States: Levels and correlates of meaning in life. Journal of Research in Personality, 42, 660-678. http://dx.doi.org/10.1016/j.jp. 2007.09.003

Steger, M. F., \& Kashdan, T. B. (2007). Stability and specificity of meaning in life and life satisfaction over one year. Journal of Happiness Studies, 8, 161-179. http://dx.doi.org/10.1007/s10902-006-9011-8

Steger, M. F., Mann, J., Michels, P., \& Cooper, T. (2009). Meaning in life, anxiety, depression, and general health among smoking cessation patients. Journal of Psychosomatic Research, 67, 353-358. http://dx.doi.org/10.1016/j.jpsychores.2009.02.006

Steger, M. F., Oishi, S., \& Kashdan, T. B. (2009). Meaning in life across the life span: Levels and correlates of meaning in life from emerging adulthood to older adulthood. Journal of Positive Psychology, 4, 4352. http://dx.doi.org/10.1080/17439760802303127

Waterman, A. S. (1993). Two conceptions of happiness: Contrasts of personal expressiveness (eudaimonia) and hedonic enjoyment. Journal of Personality and Social Psychology, 64, 678-691. http://dx.doi.org/10.1037/0022-3514.64.4.678

Zika, S., \& Chamberlain, K. (1992). On the relation between meaning in life and psychological well-being. British Journal of Psychology, 83, 133-145 http://dx.doi.org/10.1111/j.2044-8295.1992.tb02429.x 


\section{Appendix}

The Meaning in Life Questionnaire-Short Form, Presence subscale-Spanish version

\begin{tabular}{|c|c|c|c|c|c|}
\hline $\begin{array}{l}\text { MV3 (Sentido en la vida). } \\
\text { Por favor tómese unos } \\
\text { minutos para pensar en las } \\
\text { cosas que hacen que su } \\
\text { vida sea importante. ¿Qué } \\
\text { tan ciertas son para Usted } \\
\text { las siguientes } \\
\text { afirmaciones? } \\
\text { Mostrar Tarjeta } 6\end{array}$ & $\begin{array}{l}\text { Para } \\
\text { nada } \\
\text { cierta }\end{array}$ & $\begin{array}{l}\text { Algo } \\
\text { Cierta }\end{array}$ & $\begin{array}{l}\text { Bastante } \\
\text { Cierta }\end{array}$ & $\begin{array}{l}\text { Completa } \\
\text { mente } \\
\text { Cierta }\end{array}$ & $\begin{array}{l}\text { No } \\
\text { Sabe/ } \\
\text { No } \\
\text { Responde }\end{array}$ \\
\hline $\begin{array}{l}\text { a. Mi vida tiene un } \\
\text { claro sentido o } \\
\text { propósito. }\end{array}$ & 1 & 2 & 3 & 4 & 99 \\
\hline $\begin{array}{l}\text { b. He descubierto un } \\
\text { sentido satisfactorio de la } \\
\text { vida. }\end{array}$ & 1 & 2 & 3 & 4 & 99 \\
\hline $\begin{array}{l}\text { c. Tengo una clara } \\
\text { idea de lo que le da } \\
\text { sentido a mi vida. }\end{array}$ & 1 & 2 & 3 & 4 & 99 \\
\hline
\end{tabular}

The Meaning in Life Questionnaire-Short Form, Presence subscale (translated from Spanish)

1. My life has a clear meaning or purpose

2. I have discovered a satisfactory meaning in life.

3. I have a clear sense of what gives meaning to my life.

The Meaning in Life Questionnaire-Short Form, both Presence and Search subscales (original English version)

1. I am always looking to find my life's purpose. (search)

2. My life has a clear sense of purpose. (presence)

3. I have discovered a satisfying life purpose. (presence)

4. I have a clear sense of what makes my life meaningful. (presence)

5. I am seeking a purpose or mission for my life. (search)

6. I am searching for meaning in my life. (search)

(C) Michael F. Steger, 2009. This questionnaire is free for use in any research or educational capacity. Its use in commercial activity is prohibited without prior consent from the copyright-holder, Michael Steger. 